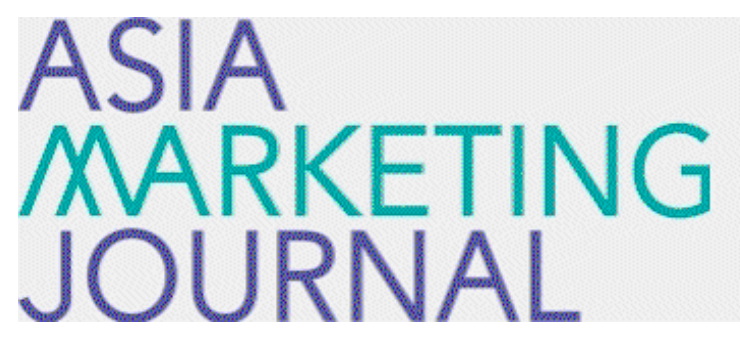

ASIA MARKETING JOURNAL

Volume 3 | Issue 1

Article 2

3-1-2001

\title{
가상시장에서의 소비자 재구매의도에 관한 연구
}

병렬 배

종채 깁

Follow this and additional works at: https://amj.kma.re.kr/journal

Part of the Marketing Commons

\section{Recommended Citation}

배, 병렬 and 깁, 종채 (2001) "가상시장에서의 소비자 재구매의도에 관한 연구," Asia Marketing Journal: Vol. 3 : Iss. 1 , Article 2.

Available at: https://doi.org/10.53728/2765-6500.1056

This Article is brought to you for free and open access by Asia Marketing Journal. It has been accepted for inclusion in Asia Marketing Journal by an authorized editor of Asia Marketing Journal. 


\title{
가상시장에서의 소비자 재구매의도에 관한 연구 *
}

\section{The Effects of Customer Satisfaction on \\ Repurchasing Intentions in Cyber Market : Moderating Effects of Perceived Risk and Product Involvement}

\author{
배병렬( 전북대학교 경영학부 조교수) \\ bbr@moak.chonbuk.ac.kr \\ 김종채( 전북대학교 경영학부 강사) \\ jckim@sbinfo.co.kr
}

\begin{abstract}
본 연구에서는 가상시장에서 인터넷쇼핑몰을 통해 제품을 구매한 경험이 있는 소비자의 재구매의도를 확인하고자 시도하였다. 인터넷쇼핑몰을 통해 제품을 재구매하기 위해서는 이전 구매경험의 만족이 결정적 요인으로 작용할 것으로 가정하였다. 이러한 쇼핑만족에 영향을 주는 요인으로는 쇼핑몰의 구조적 특성(심미성, 이용편리성), 제품특성(품질, 가격), 그리고 서비스 특성(확신성, 신뢰성, 반응성) 등을 포함하였다. 이들 요인이 쇼핑만족에 영향을 주고, 만족이 재구매의도에 영향을 줄 것으로 가정하였다. 또한, 이들 만족과 재구매의도간의 관계는 지각된 위험 및 제품관여에 따라 조절역할을 할 것으로 가정하였다. 이러한 가설들간의 관계를 분석하고자 구조방정식모델을 실시하였고, 조절변인들의 조절효과는 조절회귀분석을 통해 검증하였다. 분석결과, 모든 연구가설들은 유의적으로 나타났다. 즉 쇼핑몰의 구조적 특성, 제품특성 및 서비스 특성은 쇼핑만족에 영향을 주며, 이러한 쇼핑만족은 소비자의 재구매의도에 영향을 주는 것으로 나타났다. 또한 만족과 재구매의도간의 관계는 지각된 위험과 관여수준에 따라 조절역할을 하는 것으로 나타났다
\end{abstract}

\footnotetext{
* 논문접수: 01.08 게재확정: 01.10

이 논문은 1999 년도 전북대학교 지원 연구비에 의해 연구되었음.
} 


\section{1. 서 론}

국내 전자상거래 규모에 대한 정확한 통계가 마련되어 있지 않은 상황이지만, 정보통신부에서는 우리나라 전자상거래 규모를 지난 98년 2억 5천만 달러, 99년에는 21억 달러, 2003년에는 약 96 억 달러로 세계 10위 권에 해당하는 규모로 성장할 것이라고 예측하고 있다(국민일보, 99년 4월 6일자). 국내 전자상거래(B2B, B2C 모두) 규모는 해를 거듭할수록 성장하고 있으며, 이에 따라 인터넷쇼핑몰 및 전자상거래와 관련하여 많은 연구가 이루어졌고 또한 진행 중에 있다. 그러나 전자상거래에 대한 관심이 증가되고 있긴 하지만 아직까지 인터넷쇼핑몰에서의 소비자행동을 정확하게 설명할 수 있는 모델은 개발되어 있지 않다. 인터넷쇼핑몰에서의 소비자행동을 설명하는 데 있어 실물시장에서의 소비자행동 모델들을 그대로 적용하는 데에는 무리가 따른다고 할 수 있다. 따라서 실물시장에 대한 연구뿐만 아니라 가상시장에서의 소비자행동, 즉 온라인 소비자행동에 대한 많은 연구와 분석이 필요한 실정이다.

가상시장에서의 소비환경은 실물시장과는 상당히 다르다고 할 수 있다. 예컨대, 실물시장에서 점포애호요인으로 작용하는 점포 이미지, 점원의 태도 및 점포전환비용과 같은 개념들이 가상시장에서는 적용이 안 될 수도 있다. 가상시장에서의 쇼핑환경 가운데 가장 큰 특징은 제품구매를 위해 점포를 직접 방문하지 않아도 된다는 점이다. 즉, 컴퓨터에 연결된 네트워크상에서 소비자가 구매하고자 하는 제품을 여러 쇼핑몰을 비교한 다음 클릭하면 된다. 이와 같은 쇼핑환경으로 인해 소비자들이 특정 쇼핑몰에서 지속적인 구매를 하기란 그리 쉽지 않다. 따라서 인터넷쇼핑몰에서의 재구매의도를 확인하고 이를 관리하는 것은 쇼핑몰업체의 입장에서는 매우 중요한 의미를 갖고 있다. 특히 쇼핑몰 경쟁이 심화되고 있는 상황에서 자사 사이트에서의 지속적인 재구매행동을 유도하는 것은 수익모델의 관점에서도 바람직한 전략적 도구로 인식된다 할 것이다. 따라서 본 연구는 가상시장과 관련된 기존연구, 인터넷쇼핑몰연구 및 기존 소비자행동의 주요 이론에 대한 고찰을 통해 가상시장에서의 소비자 재구매행동을 설명해 줄 연구모형을 설정하고, 이를 실증분석을 통해 검증하고자 한다.

본 연구는 문헌연구와 실증연구를 병행하였다. 본 연구는 다음과 같이 구성되어 있다. 우선 소비자 만족과 구매행동이론, 가상시장에서의 구매행동이론 등을 검토한 다음 이를 토대로 가상시장에서의 소비자 재구매행동을 예측하기 위한 연구모형 및 가설을 설정하였다. 가설검증을 위한 자료는 설문지를 이용하여 수집하였으며, 설문의 대상자는 인터넷쇼핑몰을 이용해 한차례 이상 실제로 구매를 한 소비자로 한정하였다. 그 이유로는 본 연구는 인터넷쇼핑몰에서 구매를 경험하지 못한 소비자의 행동을 설명하려는 것이 아니라, 이미 인터넷쇼핑몰에서 구매를 경험한 소비자들의 재구매행동의도에 초점을 맞추고 있기 때문이다. 수집된 자료를 이용해 가설들을 검증하였으며, 그 결과를 토대로 관리적 시사점을 제시하였다. 


\section{2. 이론적 배경}

\section{1. 인터넷 쇼핑몰 연구}

인터넷 마케팅과 전자상거래에 대한 연구는 1990년대 중반부터 활성화되기 시작했다(Ei ghmey, 1997; Hof $f$ man and Novak, 1996; Jarvenpaa and Todd, 1997). Hof $f$ man과 Novak(1996) 은 플로우(flow) 개념을 이용하여 소비자들의 인터넷에서의 구매의도를 설명하고자 하였다. Peterson 등(1997)은 어떤 종류의 제품이 기존 유통채널을 통해 판매되며 어떤 종류의 제품이 전자상거래를 통해 판매되는 지에 대한 이론적 기반을 제공하였다. Al ba 등( 1997) 은 Interactive Home Shopping(I HS) 이 수요자와 공급자에게 미치는 장. 단점을 유통 효율성, 제품구색, 고객 정보 수집, 정보 제공, 차별적 제품제공 능력 등의 다섯 가지 경쟁우위 요인을 중심으로 비교하였다.

Ei ghmey (1997) 는 상업적 웹사이트에 대한 소비자와의 효율적인 커뮤니케이션 증진을 위해 마케팅 지각, 오락, 정보가치, 사용의 편리성, 신뢰성, 상호작용성 등의 6가지 항목을 이용하여 소비자의 반응을 분석하였다. $\mathrm{Ho}(1997)$ 는 상업적인 웹사이트의 평가기준을 비즈니스 차원과 가치창출 차원으로 분류하였다. 비즈니스 차원에는 제품 및 서비스의 촉진, 정보와 데이터의 제공, 비즈니스 거래 프로세스 등이 포함되고, 가치창출 차원에는 적절성, 고객중심성, 유통성, 지각성 등이 포함된다. Abel s 등(1997)은 웹사이트의 어떠한 특성이 사용자의 정보요구와 탐색행동, 웹사용에 영향을 주는지를 표적집단토론을 통해 분석하였다. 그 결과 웹사용에는 용이성, 내용, 구조, 연계, 외관, 독특성 등이 많은 영향을 줌을 밝혔다. Bell 과 Tang(1997) 은 6개의 사업분야(전자상거래, 오락과 여가, 재무 및 은행서비스, 정보서비스, 소매업, 여행)에 속한 회사들이 어떻게 인터넷을 업무의 경쟁적 무기로써 사용하는 가를 소비자의 관점에서 연구하였다. 총 60 개의 회사의 인터넷 사이트에 대하여 웹사이트의 접속성, 그래픽, 구조, 사용자 친숙성, 탐색, 이용성, 독창성, 온라인 거래, 이용비용 등을 설정하여 이를 분석하였다. O' Keef e와 Neeachern(1998) 은 고객의 구매의사결정을 지원하는 기초적인 '고객의사결정지원시스템(CDSS)'을 제안하였다. 그들은 고객의 구매의사결정을 돕기 위해서는 인터넷 사이트상의 충분한 내용 및 시각적인 탐색시스템 도입의 필요성을 강조하였다. Lohse와 Spill er(1998) 는 제품비교의 편리성을 위해 링크의 수, 이미지의 크기, 제품의 수, 네비게이션 형태와 같은 사용자 인터페이스 디자인의 중요성을 강조하였다.

인터넷쇼핑몰에 대한 기존연구들은 주로 쇼핑몰 이용시 소비자의 만족도를 높이거나 구매의도를 증대하기 위한 요인들을 분류하여 소비자의 반응을 분석하는 연구, 또는 상업적 웹사이트를 추진하고 있는 기업의 마케팅 기능을 충분히 제공하기 위한 기술적 요소들을 분류한 연구들이다.

\section{2. 소비자만족연구}

소비자만족은 재구매의도에 영향을 미침은 물론이고 태도변화, 상표충성도 및 구전효과에도 상당한 영향을 주기 때문에 마케팅전략상 중요한 의미를 갖는다(Jayati and 
Jackson, 1991). Westbrook(1980) 은 "만족은 단지 인지적 현상만은 아니며, 거기에는 고객이 주관적으로 만족과 관련되어 느끼는 좋은 느낌과 불만족과 관련되어 느끼는 나쁜 느낌 등의 감정 또는 느낌의 요소가 포함된다"고 하여 만족에 대한 감정적 측면을 주장하였다. 그리고 Ol iver(1981, 1989)는 만족을 “제품 획득과 소비경험과 관련된 일관적인 놀라움의 평가”로 정의한 바 있는데, 그는 감정적 반응의 특별한 유형이 만족판단의 원인이 될 수도 있고 또한 공존할 수도 있다고 주장하였다. 반면에 몇몇 연구자들은 고객이 제품성과와 규범적 기준을 비교할 때 나타나는 감정적 반응 그 자체를 만족으로 개념화하기도 하였다(Wbodruff et al., 1983; Cadot te et al., 1987).

인지적인 측면에서의 소비자만족 정의는 $\operatorname{Day}(1984)$ 의 “고객들이 특정 소비경험에 있어, 사전 기대와 지각된 실제 성과간의 차이 평가에 대해 보이는 반응”이라는 정의가 가장 일반적이다. Hunt (1976) 는 "만족은 제품의 사용이나 소비와 관련된 다양한 결과와 경험에 대해 개인이 내리는 주관적 평가의 호의성"으로 정의하고 있다.

한편, 만족이 재구매의도에 영향을 미치는지에 관한 연구가 많이 진행되고 있으며, 많은 실증연구들을 통해 고객만족이 재구매의도를 높여준다는 사실이 입증되고 있다(Bearden and Teel, 1983; Labarbera and Mazursky, 1983). O i ver(1980)의 연구에서처럼 고객만족이 구매후 태도에 영향을 미치게 되며, 이러한 태도는 계속해서 재구매의도에 영향을 미친다는 사실을 알 수 있다. 이처럼 대체적으로 고객만족과 재구매의도간의 긍정적인 관계가 밝혀지고는 있지만 그렇지 않다는 주장도 제기되고 있다. 즉, 만족은 단지 인지와 감정차원과의 판단일 수 있지만 재구매의도는 행동적 요소를 포함하고 있기 때문에, 여러 요인들에 의해 이 관계가 변할 수 있다는 것이다( Hal stead and Page, 1992).

한편, 가상시장에서의 소비자 만족에 관한 연구를 살펴보기로 한다. Szymznski 와 $\mathrm{Hi} \mathrm{se}$ (2000) 는 E- 만족을 종속변수로 편리성, 제품제공, 제품정보, 사이트디자인, 재무적 안전 등을 독립변수로 하여 이를 검증하였다. 그 결과 제품제공을 제외한 네가지 변수들이 E- 만족에 있어 유의적인 영향을 미치는 것으로 나타났다. Li ao와 Cheung( 2001) 은 소비자들의 E- 쇼핑 태도를 종속변수로 거래안전, 제품가격, 쇼핑경험, 상인품질, IT 교육, 인터넷 사용도, 네트워크속도 등의 7 가지 요소들을 독립변수로 하는 모델을 설정하였다. 그 결과 네트워크속도를 제외한 6가지 요소들이 E- 쇼핑 태도형성에 유의적인 것으로 나타났다.

\section{3. 서비스 품질연구}

Par asuraman 등 (1988) 은 서비스 품질을 “서비스의 우수성과 관련한 소비자의 전반적인 판단이나 태도”로 정의하고 있다. 또한 이들은 서비스 품질을 절대적인 개념이 아니라 고객의 지각에 따라 결정되는 상대적인 개념으로 파악하여 “소비자의 지각과 기대 사이의 차이의 방향과 정도”라고 정의하고 있다.

Gronroos(1982)에 의하면 서비스 품질은 '기술적 품질(techni cal quality)'과 '기능적 품질(functional quality)'의 결합이며, 서비스 제공활동에 있어서 후자가 특히 중요하다고 주장하였다. 기술적 품질이란 소비자가 무엇을 얻을 것인가에 관한 것으로서 편익을 제공하는 활동 그 자체에 대한 소비자의 서비스 평가를 의미하며, 기능적 품질은 소비자가 어떻게 그것을 얻을 것인가에 관한 것으로서 편익의 제공이라는 활동 그 자체가 아니라 제공의 방법에 대한 소비자 서비스의 평가를 의미한다. 서비스는 고객과의 상호작용에 의해 전달되므로 기능적 품질이 더욱 중요한 의미를 갖는다. 
Par asuraman 등(1988) 은 서비스 품질을 결정짓는 10가지 차원을 실증적 연구를 통하여 5 개 차원으로 발전시켰다. 즉 유형성, 신뢰성, 반응성, 확신성, 공감성으로 발전시켰다. 이러한 서비스 품질의 5 개 차원 가운데 인터넷쇼핑몰을 통한 제품구매에 있어서는 특히 신뢰성, 반응성 및 확신성 등이 중요하게 작용한다.

\section{4. 소비자 재구매행동연구}

소비자의 재구매행동은 상표충성도, 상점충성도 및 서비스충성도 등에 의해 설명된다. 상점충성도란 소비자가 특정기간에 어떠한 특정 상점을 지속적으로 애용하려는 성향을 말하는데, 본 연구에서는 인터넷쇼핑몰을 주로 찾는 과정을 알기 위해 특정상점을 주로 찾게 되는 과정을 설명한 Mbnroe와 Guiltinan(1975)의 이론을 중심으로 살펴보고자 한다.

소비자들이 상점을 선택하는 것도 상표를 평가할 때와 마찬가지로 근거로 삼는 기준과 상점들이 가지고 있는 특성들을 비교하게 되며, 상점에 대한 태도를 형성하고 그 중 가장 호감이 가는 상점을 선택하는 것이 일반적이다. Monroe와 Guiltinan(1975) 의 모델에 의하면 소비자들은 그들 자신에게 있어 스스로 구매욕구를 형성하게 된다. 형성된 욕구들은 상점들을 평가하는 데 있어 우선순위를 결정하는 데 이용되고, 이러한 우선순위들은 편리성, 일반적인 가격수준, 판매원, 제품선택의 폭, 매력적인 실내장식 등의 상점특성 등이 결정적인 역할을 하게 된다. 특정 상점에 대한 이미지는 광고 등의 상품전략과 소비자들이 가지고 있는 욕구에 의해 결정된다. 일단 상점이 선택된 이후에 소비자들은 상점내의 제품특성을 살피게 되고 이를 선택하게 된다. 소비자가 상점내부적인 환경과 제품을 모두 만족하게 된다면, 그 상점에 대해 호감적인 이미지를 가지게 되고, 다시 그 상점을 방문할 생각을 가지게 된다. 이와 같은 과정이 반복되어지면 상점충성도가 생기게 된다. 이러한 상점충성도는 편리성, 가격, 촉진활동 및 판매원 등의 요소들에 의해 영향을 받게 된다.

가격은 실물시장에서의 상점선택뿐만 아니라 전자상거래 환경에서의 상점선택에서도 중요하게 작용한다. 가상시장에서의 상점은 점포유지비, 재고관리비, 유통망의 통합으로 인해 저가의 제품을 공급할 것이라고 대다수의 소비자들이 인식하고 있고 또한 대다수의 인터넷쇼핑몰들은 실물시장의 매장에 비해 인하된 가격으로 제품을 공급하고 있어 많은 소비자들의 주목을 끌고 있다. 편리성과 가격 이외에도 촉진활동 및 판매원 등이 상점선택에 있어 영향을 미치게 되는데, 전자상거래 환경에서도 판매촉진활동이나 이벤트 행사와 같은 활동은 인터넷쇼핑몰의 선택에 영향을 미치게 된다. 그러나 판매원의 경우 인터넷쇼핑몰은 직접 소비자들과 접촉하여 판촉활동을 하는 것이 아니라 인터넷쇼핑몰을 이용하는 소비자들이 제품에 대한 각종의 정보, 불만사항, 의문사항 등에 대한 답변을 듣고자 하는 경우 부가적인 서비스를 제공하기 때문에 실물시장과는 다르다 할 수 있다. 실물시장에서의 판매원의 호의적인 태도와 친절은 소비자의 상점이미지 형성에 긍정적인 영향을 미치는 것과 마찬가지로 인터넷쇼핑몰에서도 역시 이러한 요소들은 인터넷쇼핑몰의 이미지 형성에 있어 유의적인 영향을 미칠 것으로 기대할 수 있다.

\section{5. 인터넷 쇼핑몰에서의 지각된 위험연구}

인터넷쇼핑몰을 통한 구매에서 지각된 위험(perceived risk)을 낮추는 것은 중요한 역할을 한다(Burke, 1997). Jarvenpaa와 Todd(1997) 는 인터넷 쇼핑몰에서 소비자들이 구매를 
할 때 중요하게 여기는 속성으로 제품인식, 쇼핑경험, 고객서비스, 소비자 위험으로 분류하고 개방형설문지를 통하여 응답내용을 범주화 하였다. 즉, 소비자들이 지각하는 위험의 종류를 경제적 위험, 사회적 위험, 기능적 위험, 개인적 위험, 프라이버시 위험으로 구분하였다. 경제적 위험이란 잘못된 구매에 대한 반품이나 교환 등이 되지 않을 것에 대한 재정적인 손실의 가능성을, 사회적 위험은 본인의 구매결정이 다른 사람들이나 사회적으로 받아들이기 어려울 위험, 기능적 위험은 구매한 제품이 기대했던 수준에 미치지 못할 가능성을 의미한다. 또한 개인적 위험은 쇼핑 도중에 소비자에게 발생될 수 있는 피해, 즉 신용카드 번호의 누출과 같은 것이고, 프라이버시 위험은 고객이 제시한 개인적 정보를 허락 없이 사용하여 사생활이 침해될 가능성을 의미한다. Li ang과 Huang(1998) 은 인터넷을 통한 거래비용에 영향을 주는 요인으로 제품 불확실성과 거래과정 불확실성을 제시하였다. 제품 불확실성은 배달된 제품이 주문시의 소비자 기대에 부응하지 못할 불확실성을 의미하며, 고객이 상품 구매 의사결정시 직접 제품을 만져보고 시험해 볼 수 없으므로, 제품의 품질에 대해 신뢰를 가지지 못하는 경우에 발생한다고 하였다. 거래과정 불확실성이란 상거래과정에서 소비자가 완전한 거래성사에 대해 확신을 가지지 못할 불확실성을 의미하며, 특히 계약체결에 대한 의구심과 전자적 지불시스템에 대한 의구심, 교환이나 A/S에 대한 의구심, 반품에 대한 의구심, 제품인도를 기다리는 데에 따르는 의구심 등을 들 수 있다.

\section{3. 연구모형 및 가설 설정}

\section{1 . 연구모형}

인터넷쇼핑몰은 웹사이트로서의 차원, 제품을 판매하는 차원, 소비자들의 쇼핑과정 상 각종의 서비스를 제공하는 차원으로 나누어 볼 수 있다. 가상시장에서의 소비자는 서비스의 수준이나 제품의 가격, 구입과 관련된 제반비용, 그리고 구매에 대한 안전성 등을 고려하여 가장 적절한 쇼핑몰 사이트에서 원하는 제품을 구매하게 된다. 그러므로, 쇼핑사이트의 관리자는 어떠한 요인들이 고객욕구에 미달되거나 불편한 지를 분석하여 이에 필요한 대응조치를 취해야 할 것이다.

인터넷쇼핑몰을 통해 제품을 구입한 경험이 있는 소비자가 다시 제품을 구매하고자 하는 재구매의도를 갖기 위해서는 기존 구매경험에 대해 만족을 해야 할 것이다. 즉 만족이 재구매의도의 선행요인으로 작용한다. 이러한 관계는 이론적 배경에서 살펴본 바와 같이 기존연구에서 상당부분 지지되고 있다. 그리고 인터넷 쇼핑만족에 영향을 줄 수 있는 요인으로는 제품특성, 서비스특성 및 쇼핑몰의 구조적 특성 등을 고려하였다. Ei ghmey (1997) 의 연구, Szymanski 와 Hi se(2000)의 연구 등에서 추출한 제품 품질 및 제품 가격 등의 변수를 제품특성변수로 이용하였다. 인터넷쇼핑몰에 대한 지각된 서비스특성도 쇼핑몰을 이용하는 소비자들의 만족 수준을 결정할 것으로 여겨진다.

Parasuraman 등(1988) 은 서비스 품질의 5가지 차원으로서 신뢰성, 반응성, 확신성 유형성 및 공감성으로 제시하였다. 이 5 가지 차원 가운데 유형성과 공감성은 전자상거래를 통한 
거래에서는 중요하게 작용하지 않을 것으로 판단되어 제외하였으며, 마지막으로, 쇼핑몰의 구조적 특성으로는 쇼핑몰 자체의 심미성과 이용의 편리성을 포함하였다.

한편, 만족과 재구매의도와의 관계는 지각된 위험(percei ved risk) 과 제품관여(product invol vement) 수준에 따라 달라질 것으로 가정하였다. 즉 지각된 위험수준과 제품관여수준을 조절변수로 설정하였다. Jarvenpaa와 Todd(1997), Li ang와 Huang(1998) 의 연구로부터 지각된 위험요인(제품위험, 거래위험, 프라이버시 침해위험) 을 고려하였고, 제품관여를 조절변수로 설정하였다. 연구모형을 그림으로 나타내면 <그림 1>과 같다.

<그림 1> 연구모형 및 가설

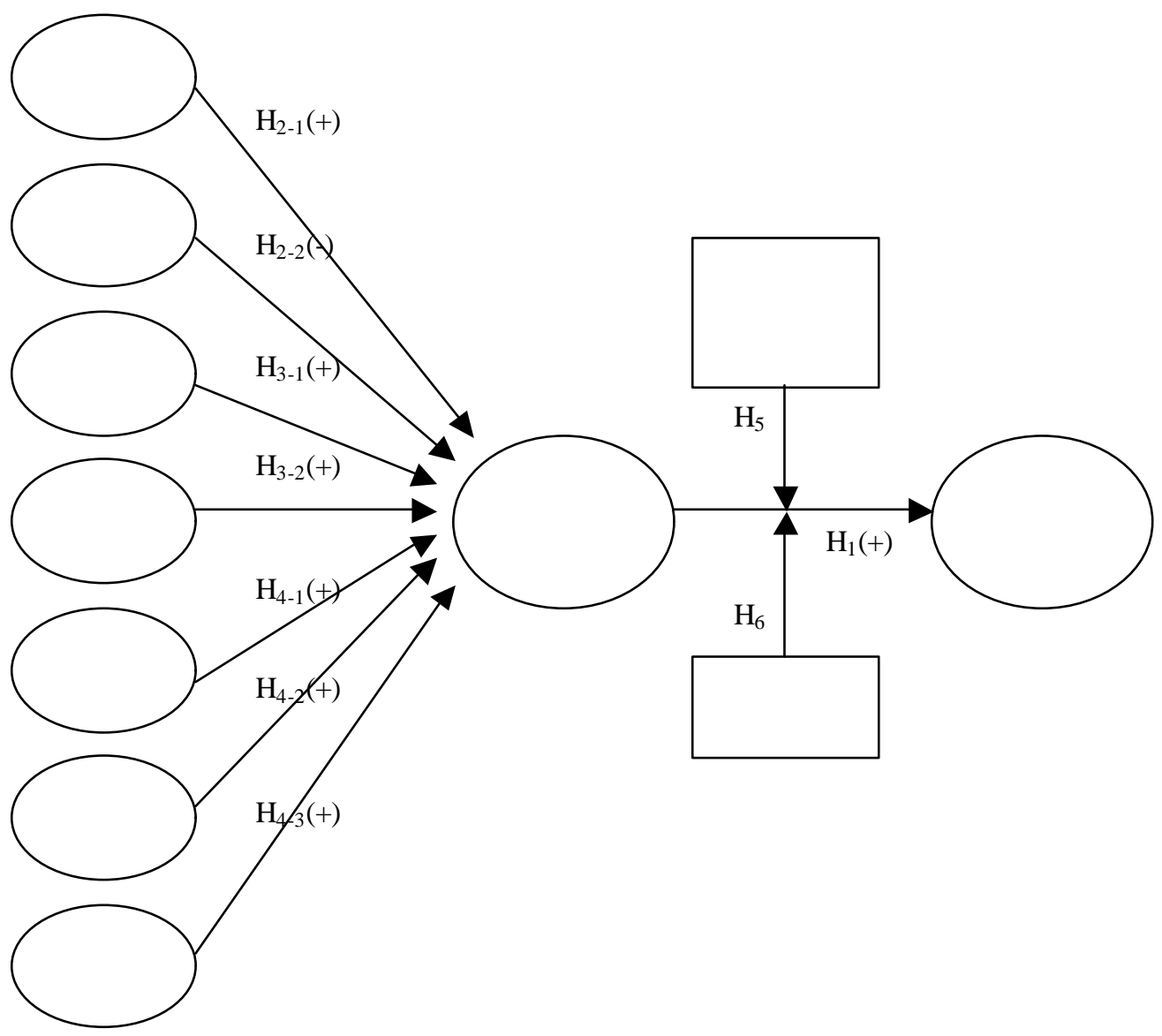

\section{2. 가설의 설정}

연구모형에 나타난 변수들의 관계를 바탕으로 하여 가설을 설정하였다. 선행연구들에서 나타난 결과들로부터 도출된 각 요인별로 가설을 세워보면 다음과 같다.

3.2.1 만족과 소비자 재구매의도간의 관계

일반적으로 소비자들의 만족이 이루어지면 재구매로 이어질 가능성이 높다(Bearden and Teel, 1983; Labarbera and Mazursky, 1983). 물론 소비자의 만족이 높더라도 재구매가 이루어지지 않은 경우도 있을 수 있지만(Hal stead and Page, 1992), 실제의 재구매행동을 
측정할 수 없기 때문에 본 연구에서는 재구매의도를 이용하여 측정하였다. 일반적으로 소비자만족은 구매후 태도에 유의적인 영향을 미치는 것으로 알려져 있고(Oliver 1981), 이러한 구매후 태도는 소비자 재구매의도 형성에 결정적인 역할을 수행한다. 이는 기존 시장에서 뿐만 아니라 인터넷쇼핑몰이라는 가상시장에서도 역시 마찬가지로 작용할 것으로 가정할 수 있다.

가설 1 : 인터넷쇼핑몰에 대한 소비자만족은 재구매의도에 정 $(+)$ 의 효과를 미칠 것이다.

3. 2.2. 제품특성, 서비스특성 및 쇼핑몰특성과 소비자 만족간의 관계

실물시장에서 제품을 구매하고 구입한 제품에 만족을 느끼는 경우 이는 소비자가 구입한 제품의 특성 즉 제품의 품질, 제품의 가격 등과 같은 특성에 의해 영향을 받는다고 할 수 있다. 소비자 자신이 구입한 제품의 품질이 높고, 비교적 저렴한 가격으로 구매하였다면 그 소비자가 제품을 구입함으로써 받게 되는 만족감은 클 것으로 기대할 수 있다. 인터넷 쇼핑몰에서 제품을 구매하는 경우도 이와 마찬가지일 것으로 가정할 수 있다(Szymanski and Hi se, 2000; Li ao and Cheung, 2001).

가설 2: 쇼핑몰에서 판매하는 제품의 특성은 소비자만족에 영향을 미칠 것이다.

가설 2-1: 쇼핑몰에서 판매하는 제품의 품질은 소비자 만족에 정(+)의 효과를 미칠 것이다.

가설 2-2: 쇼핑몰에서 판매하는 제품의 가격은 소비자 만족에 정(-)의 효과를 미칠 것이다.

인터넷 웹사이트로서의 특성인 쇼핑몰의 구조적 특성은 소비자들의 쇼핑몰 이용에 지대한 영향을 미칠 것으로 가정할 수 있다. 인터넷쇼핑몰은 웹사이트로서의 심미성, 쇼핑의 편리성 등에 따라 이를 이용하는 소비자들의 만족이 다르게 나타날 것으로 기대할 수 있다(Ei ghmey, 1997; Abel s et al., 1997; Lohse \& Spiller, 1998; Szynanski \& Hi se, 2000; Li ao \& Cheung, 2001). 인터넷쇼핑몰의 이용은 시간과 공간의 제약이 없기 때문에 오프라인에서의 거래와는 달리 여러가지 제약이 사라지는 이점이 있다. 그러나 가상공간에서 직접 시스템을 조작하여 소비자가 원하는 상품을 선택하고 구입해야 하기 때문에 시스템의 사용이 불편한 쇼핑몰에서의 구매는 만족이 덜 할 것이다. 또한 쇼핑몰은 상품을 구매하는 장소 이외의 다른 측면을 제공하고 있다. 즉, web에 몰두하도록 하는 플로우(flow) 경험은 소비자에게 새로운 즐거움을 제공한다(Hoffman and Novak, 1996). 즉, 쇼핑몰이 심미성을 갖는 사이트는 그렇지 않는 사이트에 비해 쇼핑만족에 더 많은 영향을 줄 것이다.

가설 3: 쇼핑몰의 구조적 특성은 소비자만족에 영향을 미칠 것이다.

가설 3-1: 쇼핑몰의 심미성은 소비자 만족에 정 $(+)$ 의 효과를 미칠 것이다.

가설 3-2: 쇼핑몰의 이용편리성은 소비자 만족에 정(+)의 효과를 미칠 것이다. 
지각한 인터넷쇼핑몰의 서비스 품질은 인터넷쇼핑몰을 이용하는 소비자들이 인터넷 쇼핑을 하면서 제공받는 각종의 서비스에 대한 소비자들의 지각정도라 할 수 있다. 이러한 서비스 품질은 쇼핑몰 서비스에 대한 소비자 만족에 영향을 미친다고 가정할 수 있다. 이러한 인터넷 쇼핑몰 서비스 특성으로는 지각한 신뢰성, 지각한 반응성, 지각한 확신성 등 세가지가 포함되었다(Ei ghmey, 1997; Abel s et al., 1997; Lohse \& Spiller, 1998; Szymanski \& Hi se, 2000; Li ao \& Cheung, 2001).

가설 $4:$ 지각한 인터넷쇼핑몰 서비스 특성은 소비자만족에 영향을 미칠 것이다.

가설 4-1: 인터넷쇼핑몰 서비스에 대한 지각한 신뢰성은 소비자 만족에 정 $(+)$ 의 영향을 미칠 것이다.

가설 4-2: 인터넷쇼핑몰 서비스에 대한 지각한 반응성은 소비자 만족에 정(+)의 영향을 미칠 것이다.

가설 4-3: 인터넷쇼핑몰 서비스에 대한 지각한 확신성은 소비자 만족에 정(+)의 영향을 미칠 것이다.

\section{2. 3. 조절효과}

초기의 인터넷쇼핑몰 연구들에서는 쇼핑경험, 네트워크의 속도, IT교육 및 인터넷 사용, 그리고 인구통계적인 변수들을 독립변수로 소비자들의 인터넷 쇼핑에 대한 태도, 만족 등을 종속변수로 취급하였다(Szymanski and Hse, 2000). 본 연구에서는 지각된 위험수준(제품위험, 거래위험, 프라이버시위험) 과 소비자 관여수준을 조절변수로 하여 그 영향력을 측정하고자 한다( Jarvenpaa \& Todd, 1997; Li ang \& Huang, 1998).

가설 5: 소비자들이 지각한 위험수준에 따라 소비자 만족이 소비자 재구매의도에 미치는 영향이 다를 것이다.

그 동안 소비자행동이론에서는 소비자 만족과 재구매의도간의 관계에 있어 관여가 조절변수로써의 역할을 할 수 있음을 주장하여 왔다( Sl ama and Tashchi an 1985). 본 연구에서도 인터넷쇼핑만족과 재구매의도간의 관계에서 관여가 조절역할을 할 것으로 가정하였다.

가설 6 : 소비자 관여수준에 따라 소비자 만족이 소비자 재구매의도에 미치는 영향이 다를 것이다.

\section{3. 연구조사방법}

\subsection{1 변수의 조작적 정의}

연구모형에 제시된 변수의 조작적 정의와 이와 관련된 연구들을 정리하면 <표 1>와 같다. 
<표 1> 변수의 조작적 정의

\begin{tabular}{|c|c|c|c|}
\hline 개념 & 변수 & 조작적 정의 & 관련연구 \\
\hline $\begin{array}{c}\text { 소비자 } \\
\text { 재구매행동 }\end{array}$ & 재구매의도 & 제품이나 서비스를 재구매할 의도 & $\begin{array}{l}\text { O i ver ( } 1980) \text {, } \\
\text { Li ao and } \\
\text { Cheung( 2001) }\end{array}$ \\
\hline 만족 & & $\begin{array}{c}\text { 제품만족, 쇼핑몰 자체에 대한 만족, } \\
\text { 쇼핑몰의 서비스만족 }\end{array}$ & $\begin{array}{l}\text { Szymanski and } \\
\text { Hi se( 2000) }\end{array}$ \\
\hline \multirow{2}{*}{ 제품특성 } & 품질 & 제품에 대한 소비자들의 품질지각 수준 & \multirow{2}{*}{$\begin{array}{l}\text { Javenpaa and } \\
\text { Todd( 1997) }\end{array}$} \\
\hline & 가격 & 판매제품이나 서비스의 가격의 저렴성 & \\
\hline \multirow{2}{*}{$\begin{array}{l}\text { 쇼핑몰의 } \\
\text { 구조적 } \\
\text { 특성 }\end{array}$} & 심미성 & 웹사이트의 디자인과 같은 시각적인 요소 & \multirow{2}{*}{$\begin{array}{l}\text { Pal mer and } \\
\text { Griffith( 1998) }\end{array}$} \\
\hline & 이용편리성 & $\begin{array}{c}\text { 제품이나 서비스의 탐색, 각종 정보의 } \\
\text { 제공여부 및 이용의 편리성 }\end{array}$ & \\
\hline \multirow{3}{*}{$\begin{array}{l}\text { 쇼핑몰의 } \\
\text { 서비스 } \\
\text { 특성 }\end{array}$} & 신뢰성 & $\begin{array}{c}\text { 약속된 서비스의 제공, 일관성, } \\
\text { 업무기록의 신뢰성 }\end{array}$ & \multirow{3}{*}{$\begin{array}{l}\text { Par asur aman et } \\
\text { al . (1988) }\end{array}$} \\
\hline & 반응성 & $\begin{array}{c}\text { 즉각적인 서비스의 제공, 고객의 요청에 } \\
\text { 반응하는 정도 }\end{array}$ & \\
\hline & 확신성 & 제품이나 서비스의 안전성 & \\
\hline \multirow{3}{*}{$\begin{array}{l}\text { 지각된 } \\
\text { 위험 }\end{array}$} & 제품위험 & 실제 제품과 쇼핑몰 상의 제품일치 정도 & \multirow{3}{*}{$\begin{array}{l}\text { Javenpaa and } \\
\text { Todd( 1997), Li and } \\
\text { and Huang( 1998) }\end{array}$} \\
\hline & 거래위험 & $\begin{array}{c}\text { 주문 및 지불시스템을 완벽하게 처리하는 } \\
\text { 정도 }\end{array}$ & \\
\hline & $\begin{array}{l}\text { 프라이버시 } \\
\text { 위험 }\end{array}$ & $\begin{array}{c}\text { 신용카드 정보, 개인정보 및 거래정보의 } \\
\text { 노출가능성 }\end{array}$ & \\
\hline 제품관여 & 제품관여 & $\begin{array}{c}\text { 쇼핑몰에서 구매하는 제품에 대한 개인적 } \\
\text { 중요성 }\end{array}$ & M t t al ( 1989) \\
\hline
\end{tabular}

\section{3.2. 설문의 구성 및 자료수집}

앞에 제시한 변수의 조작적 정의에 기초하여 각각의 변수들을 측정하기에 적합한 문항들을 작성하였다. 본 연구에 사용된 각 변수들은 기존 선행 연구들에서 개발된 설문을 참고하여 사용하였다. 본 조사를 위한 설문항목은 예비조사를 통해 응답자들이 이해하기 힘들거나 중복되는 설문의 경우 이를 수정하거나 제거하여 구성하였다. 1차 예비조사는 본 연구에 사용될 독립변수로 사용될 변인들의 추출을 그 목적으로 실시하였고, 2 차 예비조사에서는 1차 예비조사를 토대로 추출된 변인들을 이용, J지역에 거주하는 인터넷 사용자들을 대상으로 총 60 부를 배부하여 이 중 50 부를 회수, 각각의 응답내용을 가지고 Cronbach's Al pha계수를 이용하여 내적 일관성의 여부를 통해 신뢰성 검증을 실시하였다. 이러한 예비분석의 결과를 통해 일부 연구목적에 부적합한 항목을 제거한 후, 본 연구의 설문항목을 최종적으로 완성하였다. 
본 연구의 실증을 위해 이용된 분석방법들은 먼저 변수들에 대한 신뢰성을 검증하기 위해 Cronbach's Al pha계수를 사용하였다. 이를 통해 신뢰성이 낮게 측정되는 항목들은 이후의 분석에서 제외되었다. 또한 각 변수들에 대한 타당성검증을 위해 요인분석을 실시하였다. 응답자들의 일반적인 특성을 알아보기 위해 기술적 통계방법을 사용하였으며, 가설의 검증을 위해 구조방정식모델 및 조절회귀분석을 실시하였다. 이러한 통계분석에는 SPSSW N과 LI SREL를 이용하였다. 자료는 대인면접방법을 이용하여 인터넷 쇼핑몰 방문경험이 있는지의 여부를 확인하여 협조를 구한 후 이들을 대상으로 수집하였다. 전체 350 부의 설문을 배부하였으며 회수된 설문은 340 부 이었다. 이 가운데 불성실한 응답자를 제외하고 최종적으로 336 명의 자료가 본 연구에 사용되었다. 표본의 인구통계적 특성을 살펴보면 <표 2>와 같다.

<표 2> 인구통계적 특성에 따른 표본의 특성

\begin{tabular}{|c|c|c|c|c|c|c|c|c|c|c|c|}
\hline \multicolumn{12}{|c|}{ 성 별 } \\
\hline \multirow{2}{*}{ 남 } & \multirow{2}{*}{\multicolumn{2}{|c|}{ 152명 (46. 6) }} & \multirow{2}{*}{\multicolumn{2}{|c|}{ 여 }} & \multirow{2}{*}{\multicolumn{3}{|c|}{ 174명( 53. 4) }} & \multirow{2}{*}{ 합계 } & \multicolumn{3}{|r|}{ 326명 } \\
\hline & & & & & & & & & $(100$ & D. 0) & 10명 무응답 \\
\hline \multicolumn{12}{|c|}{ 응답자들의 연령분포 } \\
\hline 20세 미민 & \multicolumn{2}{|c|}{ 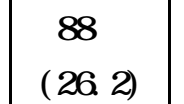 } & $\begin{array}{c}\text { 20-24세 } \\
\text { 미만 }\end{array}$ & \multicolumn{2}{|r|}{ 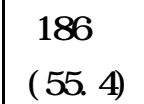 } & \multicolumn{2}{|c|}{$\begin{array}{c}\text { 25-30세 } \\
\text { 미만 }\end{array}$} & $\begin{array}{c}\text { 56명 } \\
\text { ( } 16.7)\end{array}$ & \multicolumn{2}{|c|}{ 30세 이상 } & 6명( 1.8) \\
\hline \multicolumn{12}{|c|}{ 인터넷 이용정도 } \\
\hline $\begin{array}{c}\text { 6개월 } \\
\text { 미만 } \\
\text { 2명( } 0.6)\end{array}$ & \multicolumn{2}{|c|}{$\begin{array}{l}\text { 6개월- 1년 } \\
\text { 14명( 4. 8) }\end{array}$} & \multicolumn{2}{|c|}{$\begin{array}{c}\text { 1- 2년 } \\
\text { 72명 (21. 6) }\end{array}$} & \multicolumn{2}{|c|}{$\begin{array}{c}\text { 2- 3년 } \\
\text { 144명 ( 43. 1) }\end{array} \mid$} & \multicolumn{2}{|c|}{$\begin{array}{c}\text { 3-5년 } \\
\text { 84명( 25. 1) }\end{array}$} & 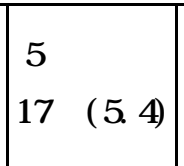 & \multicolumn{2}{|c|}{$\begin{array}{c}\text { 합계 333명 } \\
\text { (100. 0) 무응답 3명 }\end{array}$} \\
\hline \multicolumn{12}{|c|}{ 인터넷 쇼핑몰 이용시 결제방법 } \\
\hline \multicolumn{2}{|c|}{$\begin{array}{l}\text { 신용카드결제 } \\
\text { 59명( 21. 4) }\end{array}$} & \multicolumn{2}{|c|}{$\begin{array}{c}\text { 전자화폐의 } \\
\text { 이용 } \\
78 \text { 명(2.5) }\end{array}$} & \multicolumn{3}{|c|}{$\begin{array}{l}\text { 무통장입금 } \\
\text { 185명( 67. 0) }\end{array}$} & \multicolumn{2}{|c|}{$\begin{array}{c}\text { 지로용지의 } \\
\text { 이용 } \\
11 \text { 명(4.0) }\end{array}$} & $\begin{array}{c}\text { 기타 } \\
14 \text { 명(5.0) }\end{array}$ & \multicolumn{2}{|r|}{$\begin{array}{c}\text { 전체 } \\
\text { 276명( } 100.0) \\
\text { 무응답 } 60 \text { 명 }\end{array}$} \\
\hline
\end{tabular}

\section{4. 실증분석}

\section{1. 신뢰성검증}

본 연구에서 사용하고 있는 개념은 가설적인 개념으로써 응답자들의 주관적인 평가에 의해 측정된다 할 수 있다. 따라서 이들 개념들이 얼마나 신뢰성 있게 측정되었는가의 여부를 검증할 필요가 있다. 신뢰성이란 측정의 안정성, 일관성, 예측가능성 및 정확성 등이 내포된 개념으로서 측정결과가 어느 정도 일관성 있게 측정되었는가를 의미한다. 동일한 개념을 여러 개의 복수문항으로 측정을 하는 경우에 보통 Cronbach's Al pha 계수를 이용하는데, 본 연구에서도 이를 이용하여 내적일관성의 여부를 측정하였다. <표 $3>$ 에 
제시된 Cronbach's Al pha 계수들을 살펴보면, 모든 측정변수들의 수치가 0.75 이상인 것을 알 수 있다. 일반적으로 신뢰도계수의 값이 0.6 이상이면 유효하게 사용할 수 있기 때문에(채서일, 1997), 본 연구의 검증을 위해 사용될 변수들은 전체적으로 신뢰도가 높은 편이라고 할 수 있다.

<표 3> 변수의 신뢰도계수

\begin{tabular}{|c|c|c|c||c|c|c|c|}
\hline 변수명 & $\begin{array}{c}\text { 궁목 } \\
\text { 의수 }\end{array}$ & $\begin{array}{c}\text { Cronbach' s } \\
\text { a }\end{array}$ & $\begin{array}{c}\text { St andar i zed } \\
\text { i t em a }\end{array}$ & 변수명 & $\begin{array}{c}\text { 구분목 } \\
\text { 의수 }\end{array}$ & $\begin{array}{c}\text { Cr onbach' s } \\
\text { a }\end{array}$ & $\begin{array}{c}\text { St andar i zed } \\
\text { i t em a }\end{array}$ \\
\hline \hline 재구매의도 & 3 & 0.9600 & 0.9602 & 반응성 & 3 & 0.8663 & 0.8675 \\
\hline 만족 & 3 & 0.8290 & 0.8288 & 확신성 & 3 & 0.9289 & 0.9296 \\
\hline 제품 품질 & 3 & 0.7828 & 0.8156 & 제품위험 & 4 & 0.8358 & 0.8355 \\
\hline 제품 가격* & 2 & 0.6262 & 0.6265 & 거래위험 & 3 & 0.8307 & 0.8326 \\
\hline 심미성 & 4 & 0.7690 & 0.7335 & 프라이버시 위험 & 3 & 0.9256 & 0.9257 \\
\hline
\end{tabular}

* 제품 가격 3 번 문항은 제거되었음.

\section{2. 타당성 검증}

타당성은 측정도구가 측정하고자 하는 개념이나 속성을 얼마나 정확하게 측정하였는가를 의미한다. 타당성을 검증하는 통계적인 방법으로는 흔히 요인분석이 사용되고 있는데, 요인분석을 실시하기 위해서는 표본수가 항목수의 4-5배 이상이 되어야 한다는 조건이 있으며(채서일, 1997), 본 연구에서는 이러한 조건을 충족시키고 있기 때문에 요인분석을 통해서 타당성검증을 실시하였다.

요인의 추출에 있어서는 자료의 손실을 최소화하면서 요인의 수를 적절히 줄이기 위한 주성분분석을 사용하였고(이영준, 1993), 요인의 회전으로는 직각회전방식(VARI MAX) 을 선택하였다. 요인분석의 결과, <표 4>에 나타난 바와 같이 58 개의 항목들이 13 개의 요인으로 구분되었다. 분석에 사용한 항목들이 모두 요인적재량이 해당요인에 대하여 모두 높게 나타나 집중타당성(convergent validity)이 있으며, 각각의 요인으로 묶였기 때문에 판별타당성(di scriminant val i dity)이 있는 것으로 나타났다. 13가지 요인들의 설명분산은 64. $66 \%$ 로 높게 나타났다. 
<표 4> 요인분석 결과

\begin{tabular}{|l|c|c|c|c|}
\hline \multicolumn{1}{|c|}{ 변수 } & 항목의 수 & 고유치 & 설명분산 & 요인적재량 범위 \\
\hline 재구매의도 & 3 & 1.288 & 2.111 & $0.753 \sim 0.871$ \\
\hline 만족 & 3 & 2.182 & 3.575 & $0.763 \sim 0.898$ \\
\hline 제품의 품질 & 3 & 3.066 & 5.026 & $0.801 \sim 0.827$ \\
\hline 제품의 가격 & 2 & 1.055 & 1.729 & $0.714 \sim 0.785$ \\
\hline 심미성 & 4 & 2.510 & 4.023 & $0.845 \sim 0.901$ \\
\hline 이용의 편리성 & 4 & 1.326 & 2.175 & $0.766 \sim 0.831$ \\
\hline 신뢰성 & 4 & 1.865 & 3.058 & $0.712 \sim 0.888$ \\
\hline 반응성 & 3 & 2.489 & 4.080 & $0.853 \sim 0.898$ \\
\hline 확신성 & 3 & 1.956 & 3.206 & $0.796 \sim 0.865$ \\
\hline 제품위험 & 4 & 2.183 & 3.577 & $0.665 \sim 0.893$ \\
\hline 거래위험 & 3 & 2.532 & 4.150 & $0.798 \sim 0.908$ \\
\hline 프라이버시 위험 & 3 & 7.044 & 11.548 & $0.722 \sim 0.805$ \\
\hline 제품 관여수준 & 9 & 10.273 & 16.841 & $0.738 \sim 0.965$ \\
\hline
\end{tabular}

\section{3. 연구가설의 검증}

\subsection{1 소비자 만족과 재구매의도 영향관계 검증}

본 연구에서 설정한 연구모형을 검증하기 위하여 구조방정식모델을 실시해 모형의 적합도를 확인하고, 모형상의 모수들을 동시에 추정하였다. 모수 추정법은 측정변수들의 정규분포성을 가정하는 최우추정법(maximulikel i hood method)을 이용하였다. 연구모형의 검증을 위해 총 48 개의 문항 가운데 제품위험, 거래위험, 프라이버시위험 및 관여수준 등의 19 개 문항을 제외한 29 개 관찰변수 측정치의 공분산행렬을 원자료로 이용하였다.

본 연구에서 제시한 전체적인 연구모형의 GFI 는 0.90로 비교적 적합한 것으로 나타났으며, 수정적합지수( $\mathrm{AGFI})$ 도 0.87 으로 비교적 괜찮은 수준인 것으로 나타났다. NFI 는 0.91, CFI는 0.93으로 나타나 전반적인 모델 적합도는 수용할 만한 수준인 것으로 나타났다. 그러나, $\chi^{2}=697.67(\mathrm{df}=246)$ 으로 나타나 유의적인 것으로 나타나기는 했으나, $\chi^{2}$ 는 표본크기에 민감한 단점이 있으므로( Hair et d., 1998), 본 연구의 표본규모(336)를 고려했을 때 $\chi^{2}$ 로 모델적합도를 판단하는 데에는 무리가 있을 것으로 판단된다. 본 연구에서 설정한 가설을 검정하기 위해 경로별 결과를 토대로 이론변수들간의 관계를 요약해보면 <표 5>와 같다.

먼저 인터넷 쇼핑몰에 대한 소비자 만족과 재구매의도와의 관계를 가정한 가설 1 의 경우, 유의적인 정 $(+)$ 의 효과를 보이는 것으로 검증되었다. 인터넷 쇼핑몰에서 판매하는 제품특성이 소비자 만족에 영향을 미칠 것이라는 가설 2의 경우를 살펴보면, 제품 품질은 유의적인 정 $(+)$ 의 효과를, 제품 가격은 유의적인 부(-)의 효과를 각각 보이는 것으로 검증되어 가설 2 역시 채택되었다.

쇼핑몰의 구조적 특성의 경우, 쇼핑몰 심미성과 쇼핑몰의 이용편리성 각각은 유의적인 
정 $(+)$ 의 효과를 보이는 것으로 검증되어 가설 3 역시 채택되었다. 인터넷 쇼핑몰에서 제공되는 지각한 서비스 품질이 소비자 만족에 영향을 미칠 것이라는 가설 4 의 경우 본 연구에서 설정한 신뢰성, 반응성, 확신성 모두가 유의적인 정(+)의 효과를 가지는 것으로 검증되어 가설 4는 채택되었다.

<표 5> 구조방정식분석 결과

\begin{tabular}{|c|c|c|c|c|c|}
\hline 구분 & 경로설정 & $\begin{array}{l}\text { 경로 } \\
\text { 계수 }\end{array}$ & T값 & 가설번호 & $\begin{array}{l}\text { 가설의 } \\
\text { 채택여부 }\end{array}$ \\
\hline $\begin{array}{c}\text { 만족과 } \\
\text { 재구매의도관계 }\end{array}$ & $\begin{array}{c}\text { 소비자 만족 -> } \\
\text { 소비자 재구매의도 }\end{array}$ & 0.73 & 13. 89 & 가설 1 & 채택 \\
\hline \multirow{2}{*}{$\begin{array}{c}\text { 쇼핑몰에서 } \\
\text { 판매하는 제품특성 }\end{array}$} & 제품 품질 - > 소비자만족 & 0.41 & 3. 85 & 가설 2-1 & 채택 \\
\hline & 제품 가격 - > 소비자 만족 & -0.22 & -2.51 & 가설 2-2 & 채택 \\
\hline \multirow{2}{*}{$\begin{array}{c}\text { 쇼핑몰의 구조적 } \\
\text { 특성 }\end{array}$} & 심미성 - > 소비자 만족 & 0.11 & 2. 07 & 가설 3-1 & 채택 \\
\hline & 이용편리성 -> 소비자 만족 & 0.12 & 2. 31 & 가설 3-2 & 채택 \\
\hline \multirow{3}{*}{$\begin{array}{c}\text { 지각한 쇼핑몰 } \\
\text { 서비스 특성 }\end{array}$} & 신뢰성 - > 소비자 만족 & 0.41 & 4. 14 & 가설 3-3 & 채택 \\
\hline & 반응성 -> 소비자 만족 & 0.34 & 2. 76 & 가설 4-1 & 채택 \\
\hline & 확신성 - > 소비자 만족 & 0.42 & 3. 27 & 가설 4-2 & 채택 \\
\hline
\end{tabular}

4. 3.2. 지각된 위험과 관여의 조절효과

소비자 만족이 소비자 재구매의도에 영향을 미치는 과정에서 지각된 위험수준과 제품 관여수준이 조절변수로서 작용하는 지를 알아보기 위해 변수값들을 평균변환시킨 후 곱모형의 회귀분석을 이용하여 이를 검증하였다. 즉, 상호작용항목들과 조절변수간의 높은 상관이 초래할 수 있는 다중공선성의 문제와 등간척도로 측정된 경우 척도의 종속성문제 등을 최대한 줄일 수 있어 모든 변수값들을 평균변환시킨 다음 각 독립변수들의 상호작용효과를 곱의 형태로 포함된 곱모형을 통해 이를 검증하였다(Irwin and $\mathrm{McClelI}$ and 2001)

조절회귀분석 결과, 소비자 만족이 소비자 재구매의도에 미치는 영향에 대한 지각된 위험수준과 제품관여수준 모두 유의적인 조절효과를 보이는 것으로 검증되었다. 지각된 위험수준의 경우, $\mathrm{T}$ 값이 $-2.562(\mathrm{sig} .=0.011<0.05$ ) 이었으며, 제품관여수준의 경우 T값이 2. 029( si g. $=0.043<0.05$ ) 로서 각각 유의적이었다. 그러므로, 지각된 위험수준이 높은 경우에는 만족하더라도 재구매의도는 떨어진다고 해석할 수 있다. 제품관여는 만족과 재구매의도간에 정적인 조절역할을 하는 것으로 나타났다. 따라서 만족과 재구매의도간의 관계는 만족이 높으면 재구매의도가 높아지고, 만족이 낮아지면 재구매의도는 낮아지는 것으로 해석할 수 있다. 이때 지각된 위험수준과 제품관여수준은 소비자 재구매의도에 
대하여 독립적인 변수로써의 역할을 하지는 못하는 것으로 검증되었다. 따라서 조절효과에 대한 가설 5 과 가설 6 은 모두 채택되었다.

<표 6> 조절회귀분석 결과

\begin{tabular}{c|c|c|c|c|c}
\hline 독립변수 & B & St d. Error & Bet a & T & Si g. \\
\hline \hline 상 수 & 1.176 & 0.492 & & 2.390 & 0.017 \\
\hline 소비자 만족 & 0.575 & 0.168 & 0.422 & 3.423 & 0.001 \\
\hline 지각된 위험 & -0.247 & 0.129 & -0.181 & -1.917 & 0.056 \\
\hline 제품관여 & 2.410 & 1.334 & 0.469 & 1.807 & 0.072 \\
\hline 소비자 만족 * 지각된 위험 & -4.756 & 1.856 & -0.570 & -2.562 & 0.011 \\
\hline 소비자 만족 * 제품관여 & 0.371 & 0.183 & 0.317 & 2.029 & 0.043 \\
\hline \hline
\end{tabular}

R Square $=0.579 \quad$ Adj ust ed $\mathrm{R}$ Squar e $=0.573$

$\mathrm{F}=89.710$

Si g. $F=0.000$

\section{5. 결론}

\section{1. 연구의 결과와 시사점}

본 연구는 가상공간에서 인터넷 쇼핑을 즐기는 소비자들을 대상으로 하여 이들의 재구매의도를 분석하고자 시도한 것이다. 즉, 인터넷쇼핑몰에서의 소비자 재구매행동에 영향을 주는 요인으로 쇼핑몰에서 판매하는 제품의 특성, 쇼핑몰의 구조적 특성, 지각한 쇼핑몰의 서비스 품질특성 등을 설정하여 소비자들의 인터넷쇼핑몰 만족과 쇼핑몰 재구매의도와의 관계를 검증하였다.

이러한 검증을 위해 Peter son 등(1995) 의 연구, Parasuraman 등(1988) 의 서비스 품질모형, Jarvenpaa와 Todd(1997) 의 연구, Li ang과 Huang(1998) 연구 등을 그 토대로 하여 추출된 개념들을 이용, 본 연구의 개념적인 모형을 설계하였다. 연구모형을 토대로 개념간의 관계를 가설로 세웠고, 인터넷쇼핑몰을 방문해 구매한 경험이 있고 현재 인터넷쇼핑몰을 이용하고 있는 인터넷 사용자들만을 대상으로 하여 대인면접을 통한 설문조사를 이용해 실증자료를 수집하였다. 실증분석의 경우 선정된 표본 중 최종적으로 회수된 336 부의 설문지를 신뢰성검증과 요인분석을 통하여 신뢰성과 타당성이 검증된 자료로 변환하여 실증분석에 이용하였다. 수집된 자료의 신뢰성과 타당성 분석결과를 통해 제품 가격3의 변수만을 제외하고 나머지 변수들이 이후의 검증에 사용되었다.

본 연구에서 설정한 연구모형을 검증하기 위해 LI SREL를 이용해 모형을 검증하였고 SPSSW N을 이용해 조절회귀분석을 실시하였다. 검증 결과, 소비자만족은 소비자의 재구매의도에 유의적으로 영향을 미치는 것으로 나타났다(가설1). 소비자 만족의 경우 쇼핑몰에서 판매하는 제품특성 중 제품 품질(+의 효과)과 제품 가격(-의 효과)이 모두 
유의적인 영향을 미치는 것으로 나타났으며, 쇼핑몰의 구조적 특성의 경우 쇼핑몰 심미성과 이용편리성이 유의적인 것으로, 지각한 쇼핑몰 서비스 품질특성 중에는 신뢰성, 반응성, 확신성 각각이 유의적인 요인인 것으로 검증되었다.

인터넷쇼핑몰을 이용하는 소비자들의 지각된 위험수준과 제품관여수준의 조절효과를 알아보기 위한 조절회귀분석의 결과를 살펴보면, 지각된 위험수준의 경우 소비자만족이 소비자 재구매 의도에 있어 유의적인 부(-)의 조절역할을 수행하는 것으로 검증되었다. 따라서 소비자가 만족하더라도 지각된 위험수준을 높게 지각하면 재구매의도가 떨어지기 때문에 인터넷쇼핑몰 관리자는 소비자의 지각된 위험수준을 낮추려는 노력이 필요할 것이다. 제품관여수준의 경우 소비자 만족이 소비자 재구매의도에 있어 유의적인 정 $(+)$ 의 조절효과를 보이는 것으로 검증되었다. 따라서 소비자의 제품관여가 높은 경우에는 만족할수록 재구매의도가 높아진다고 볼 수 있다. 그러나 지각한 위험수준과 제품관여수준은 독립적으로 소비자 재구매의도에 영향을 미치지는 않는 것으로 검증되었다.

\section{2. 연구의 한계 및 향후 연구 과제}

본 연구에서 나타난 검증결과 및 이의 해석은 본 연구가 지니고 있는 몇 가지의 한계점으로 인해 그 적용에 있어 신중해야 할 것이며, 향후 이러한 문제점들을 해결하기 위한 연구가 수행되어야 할 것이다.

첫째, 본 연구에서는 연구대상을 인터넷쇼핑몰을 이용해 제품을 구매한 경험이 있는 이용자로 한정하고 있다. 그러므로 여러 쇼핑몰에서 구매한 경험이 있는 경우, 특정 쇼핑몰에서는 만족한 감정을 갖고 있으나 다른 특정 쇼핑몰에 대해서는 만족하지 않는 감정이 혼합되어 있을 가능성이 있다. 이러한 경우, 만족이 재구매의도에 미치는 영향은 상대적으로 낮게 나타날 가능성이 있다. 따라서 향후의 연구에서는 특정 쇼핑몰별로 연구를 할 필요성이 있다. 둘째, 본 연구는 시간의 경과에 따른 변화를 충분히 반영하지 못한 횡단적인 방법을 택하였기 때문에, 인터넷 쇼핑몰의 구조적 특성이 변화하는 경우 소비자들의 쇼핑만족 및 재구매의도가 변화할 것으로 예상할 수 있다. 그러나 본 연구는 이러한 영향력은 파악하지 못하고 있다.

이러한 여러 한계점들을 극복하고 보다 의미 있는 결과를 얻기 위하여 추후의 연구들에서는 다음과 같은 점들이 반영되어야 할 것이다.

첫째, 보다 엄밀한 사전조사 과정을 통해 인터넷 쇼핑몰에서의 구매 및 재구매행동이라는 결과에 영향을 미칠 것으로 예상되는 변수들에 대한 보다 정확한 연구과정과 측정도구 개발과정이 필요할 것이다. 즉 인터넷쇼핑만족에 영향을 줄 수 있는 또 다른 변수(예, 배달의 신속성 및 안정성)를 고려한 연구가 필요할 것이다. 둘째, 횡단면적인 조사에만 치우치지 않고 종단적 조사를 병행하여 보다 정확하게 인터넷 쇼핑몰에서의 재구매행동을 예측할 필요가 있다. 셋째, 본 연구에서는 지각된 위험수준과 관여수준을 조절변수로 사용하였으나, 몇몇 문헌들에서는 이 변수들을 독립변수로도 사용하고 있다. 따라서 추후의 연구에서는 이 변수가 정확히 어떠한 역할을 수행하는지도 살펴보아야 할 것이다. 
이영준, SPSS/PC+를 이용한 다변량분석, 석정, 1993.

채서일, 사회과학조사방법론, 학현사, 1997.

Abels, E. G., M. D. White, and K. Hahn(1997), "Identifying User-Based Criteria for Web Pages," Internet Research, 7(4), pp. 252-262.

Alba, J., J. Lynch, B. Weitz, C. Janiszewski, R. Lutz, A. Sawyer, and S. Wood(1997), “Interactive Home Shopping : Consumer, Retailer, and Manufacturer Incentives to Participate in Electronic Marketplaces," Journal of Marketing, 61(July), pp. 38-53.

Bearden, W. O. and J. E. Teel(1983), "Selected Determinants of Consumer Satisfaction and Complaint Reports,” Journal of Marketing Research, 20(Feb.), pp. 21-28.

Bell, H., and N. K. H. Tang(1997), “The Effectiveness of Commercial Internet Web Sites: Marketplaces," Management Science, 43(12), pp. 1676-1692.

Burke, R. R.(1997), “Do you See What I See The Future of Virtual Shopping," Journal of the Academy of Marketing Science, 25(4), pp. 352-360.

Cadotte, E R., R. B. Woodruff, and R. L. Jenkins(1987), "Expectations and Norms in Models of Consumer Satisfaction,” Journal of Marketing Research, 24(August), pp. 305-314.

Dallaert, B. and B. Kahn(1999), "How Tolerable is Delay? Consumer's Evaluations of Internet Web Sites After Waiting," E-Commerce Research Forum, 1(1).

Day, R L.(1984), "Modeling Choices Among Alternative Responses to Dissatisfaction," Advances in Consumer Research, 11, pp. 496-499.

Eighmey, J.(1997), "Profiling User Response to Commercial Web Sites," Journal of Advertising Research, 37(May-June), pp. 59-66.

Engel, J. F., R. D. Blackwell and P. W. Miniard(1982), Consumer Behavior, 4th ed., New York: Dryden Press.

Gronroos, C.(1982), “A Service Quality Model and Its Marketing Implications,” European Journal of Marketing, 18(4), pp. 36-44.

Hair, J. F., R. E. Anderson, R. L. Tatham, W. C. Black(1995), Multivariate Data Analysis with Readings, 4th ed., Prentice-Hall.

Ho, J.(1997), "Evaluating the World Wide Web: A Global Study of Commercial Sites," Journal of Computer-Mediated Communication, June, http://www.ascusc.org/ jcmvol13/ issue1/ho.html.

Hoffman, D. L. and T. P. Novak(1996), "Marketing in Hypermedia Computer-Mediated Environments: Conceptual Foundations," Journal of Marketing, 66, pp. 50-68.

Hunt, H. K. (1976), "CS/D: Overview and Future Research Direction," Conceptualization and Measurement of Consumer Satisfaction and Dissatisfaction, pp. 455-488.

Irwin, J. R. and G. H. McClelland(2001), "Misleading Heuristics and Moderated Multiple Regression Models," Journal of Marketing Research, 38(1), pp. 100-109.

Jarvenpaa, S. J. and P. A. Todd(1997), "Consumer Reactions to Electronic Shopping on the World Wide Web,” International Journal of Electronic Commerce, 1(2), pp. 59-88.

Jayati, R. and A. Jackson(1991), "Service Satisfaction : An Exploratory Investigation of Three Model," Advances in Consumer Research, 18, pp. 603-610.

Labarbera, P. A. and D. Mazursky(1983), “A Longitudinal Assessment of Consumer Satisfaction/Dissatissfaction: The Dynamic Aspect of the Cognitive Process," Journal of Marketing Research, 20(Nov.), pp. 393-404.

Liang, T. P. and J. S. Huang(1998), “An Empirical Study on Consumer Acceptance of Products in Electronic Markets : a Transaction Cost Model," Decision Support Systems, 24, pp. 29-43. 
Liao, M. and T. Cheung(2001), "Internet-Based E-Shopping and Consumer Attitudes : An Empirical Study," Information and Management, 38, pp. 299-306.

Lohse, G. L. and P. Spiller(1998), "Electronic Shopping," Communications of ACM, 41(7), pp. 81-86.

Mittal, B.(1989), “Measuring Purchase-Decision Making,” Psychology and Marketing, 6(2), pp. 147-162.

Monroe, K. B. and J. P. Guiltinan(1975), "A Path-Analytic Exploration of Retail Patronage Influence," Journal of Consumer Research, 2(June), pp. 19-28.

O'Keefe, R. and M. Mceachern(1998), "Web-Based Customer Decision Support Systems," Communications of ACM, 41(3), pp. 71-78.

Oliver, R. L.(1980), “A Cognitive Model of the Antecedents and Consequences of Satisfaction Decisions," Journal of Marketing Research, 17(Nov.), pp. 460-468.

Oliver, R. L.(1981), “Measurement and Evaluation of Satisfaction Process in Retail Setting,” Journal of Retailing, 57(Fall), pp. 25-48.

Oliver, R. L.(1989), "Processing of the Satisfaction Response in Consumption: A Suggested Framework and Research Propositions," Journal of Consumer Satisfaction, Dissatisfaction and Complaining Behavior, 2, pp. 1-16.

Palmer, J. W. and D. A. Griffith(1998), “An Emerging Model of Web Site Design for Marketing, Communications of the ACM, 41(3), pp. 44-51.

Parasuraman, A., V. A. Zeithmal \& L L. Berry(1988), "SERVQUAL: A Multiple -Item Scale for Measuring Consumer Perceptions of Service Quality," Journal of Retailing, 64, pp. 12-40.

Peterson, R. A., S. Balasubramanian, and B. J. Bronnenberg(1997), "Exploring the Implications of the Internet for Consumer Marketing," Journal of the Academy of Marketing Science, 25, pp. 329-346.

Slama, M. E. and A. Tashchian(1985), "Selected Socio-Economic and Demographic Characteristics Associated with Purchasing Involvement," Journal of Marketing, 49(Win.), pp. 72-82.

Swan, J. E. and L J. Comb(1976), "Product Performance and Consumer Satisfaction: A New Concept," Journal of Marketing, 40, pp. 25-33.

Szymanski, D. M and R. T. Hise(2000), "E-satisfaction: An Initial Examination," Journal of Retailing, 76(3), pp. 309-332.

Westbrook, R. A.(1980), “Interpersonal Affective Influences upon Consumer Satisfaction with Products," Journal of Consumer Research, 7(June), pp. 49-54.

Woodruff, R B., E. R. Cadotte, and R L. Jenkins(1983), "Modeling Consumer Satisfaction Process Using Experience-Based Norms," Journal of Marketing Research, 20(August), pp. 296-304. 